Relato crítico de uma experiência didática acerca de uma temática científica aplicada na educação básica: algumas reflexões epistemológicas e a defesa de um ensino de ciências fundamentado na argumentação dialógica

Ricardo Rangel Guimarães

Pós-Doutorando do Programa de Pós-Graduação em Ensino de Física

Instituto de Física - Universidade Federal do Rio Grande do Sul

Neusa Teresinha Massoni ${ }^{l}$

Programa de Pós-Graduação em Ensino de Física

Instituto de Física - Universidade Federal do Rio Grande do Sul

Porto Alegre - RS

\title{
Resumo
}

Este trabalho tem como objetivo principal fazer um relato critico e propor reflexões epistemológicas sobre o uso da metodologia de ensino por argumentação em uma atividade de divulgação de uma temática científica desenvolvida na disciplina de Física, em uma turma de ensino médio de uma escola pública estadual de educação básica de Porto Alegre (RS). Tal atividade, desenvolvida no formato de um júri simulado, foi pensada e elaborada para ser aplicada na forma de um micromódulo de ensino em que assumimos ser possível, mediante este recurso pedagógico, atingir um nivel de aprendizado adequado a essa faixa etária, através do debate e da argumentação dialógica. Buscamos, para tanto, oferecer elementos para que os estudantes se envolvam em tal estratégia no ambiente de sala de aula e desenvolvam habilidades de argumentação. Os referenciais teórico-metodológicos utilizados nesta pesquisa são os do ensino por argumentação articulado a uma epistemologia que desenvolva virtudes intelectuais e o pensamento crítico no estudante. O que se pretende neste trabalho, que é parte de uma investigação mais abrangente, é fazer através do relato crítico do

\footnotetext{
Critical report of a didactic experience about an applied scientific theme in basic education: some epistemological reflections and the defense of a science teaching based on dialogic argumentation

* Recebido: maio de 2019. Aceito: abril de 2020.

${ }^{1}$ E-mails: rirangel@bol.com.br; neusa.massoni@if.ufrgs.br
} 
estudo de caso, uma defesa desses referenciais como potencializadores para a promoção de uma educação científica mais autônoma e reflexiva.

Palavras-chave: Ensino de Física; Argumentação; Epistemologia; Pensamento Crítico; Educação Científica.

\begin{abstract}
This work has as main objective to make a critical report and to propose epistemological reflections on the use of the methodology of teaching by argumentation in an activity of dissemination of a scientific theme developed in the discipline of Physics in a high school class of a state public school of education of Porto Alegre (RS). This activity, developed in the form of a simulated jury, was conceived and elaborated to be applied in the form of a micromodule of teaching in which we assume that it is possible, through this pedagogical resource, to reach a level of learning appropriate to this age group, through the critical debate and the dialogical argumentation. Therefore, we seek to offer elements for students to engage in such a strategy in the classroom environment and develop argumentative skills. The theoretical-methodological references used in this research are that of teaching by argument and also that of an epistemology that develops intellectual virtues and critical thinking in the student. What is wanted in this work, which is part of a more comprehensive investigation, is to do through the critical report of the case study a defense of these referential potentials for the promotion of a more autonomous and reflexive scientific education.
\end{abstract}

Keywords: Teaching; Argumentation; Epistemology; Critical Thinking; Scientific Education.

\title{
I. Introdução
}

O que vem a ser, ao fim e ao cabo, um aprendizado adequado e correto na educação, em especial na educação científica, e de que modo ele pode ser alcançado, pressupondo-se que tal fim seja o objetivo maior de todo processo educativo? Ao iniciarmos nossa investigação com este questionamento, estamos, de antemão, fazendo alguma espécie de juízo de valor sobre qual o melhor aprendizado na educação, tendo como pano de fundo um histórico de metodologias de ensino tradicionais, em que as Ciências são trabalhadas de forma mecânica, pautada na transmissão de informações, a partir da apresentação de fórmulas, descrições, enunciados e leis (SASSERON; MACHADO, 2017, p. 10) e na 
memorização destes, o que constitui grande parte do estado da arte da educação clássica e canônica, desde os primórdios até a contemporaneidade. Nos últimos séculos, muitos teóricos da educação, pedagogos e pesquisadores trouxeram para contrastar com este estado da arte novas estratégias e novas abordagens de ensino, como, por exemplo, as metodologias ativas, a aprendizagem baseada em projetos, a sala de aula invertida e o ensino baseado em argumentação, apenas para citar alguns exemplos.

Nosso foco no presente estudo se centrará nesta última metodologia, essencialmente no que tange à sua estruturação teórica e aplicação na educação científica, no potencial da argumentação como uma ferramenta útil e eficiente para o ensino e o aprendizado em Ciências, particularmente no ensino de Física e de Astronomia no contexto da educação básica. Essencialmente conectado com o ensino centrado no processo argumentativo está, também, o desenvolvimento de pensamento crítico e de virtudes intelectuais através de uma Epistemologia das virtudes fundamentada em aspectos éticos e sociais (alguns autores que discutem sob este viés, por exemplo: BAHER, 2010; BAHER, 2014; HODSON, 2004; SIEGEL, 2005; SMITH; SIEGEL, 2004), onde a formação responsável e cidadã seria o objetivo maior, como um fim em si mesmo, de uma educação científica reflexiva, valorosa e socialmente justa (por exemplo, KOLSTO, 2001). Nessa linha, a fim de ilustrar com um exemplo empírico estas questões, como laboratório de pesquisa, foi aplicado um micromódulo de ensino em uma turma do segundo ano do ensino médio de uma escola pública de Porto Alegre (RS), tomando como tema, dentro do campo da divulgação científica, a missão tripulada da Apollo 11 e consequentemente a chegada do homem à Lua. Um segundo objetivo é contribuir com o debate, que há décadas está presente na literatura da área, no sentido de que é relevante discutir História e Filosofia da Ciência na educação básica (por exemplo, MATTHEWS, 1995; LEDERMAN, 1992) como estratégia à construção do pensamento crítico, mas que ainda hoje é pouco presente na sala de aula (MASSONI, 2010; BOARO; MASSONI, 2018). A fim de introduzir a questão da missão tripulada da Apollo 11 em sala de aula, que suscita bastante discussão acerca de sua veracidade em nível de senso comum, foi apresentado um breve resumo dos programas espaciais estadunidense e soviético da segunda metade do século XX com o objetivo de contextualizar os estudantes na temática a ser trabalhada e investigada, bem como de problematizar e incitar uma investigação dos teóricos da conspiração sobre a ida do homem à Lua para, a partir daí, estabelecer as condições básicas e um cenário propício ao debate argumentativo contrapondo estas posições, bem como estimulando também, e tanto quanto, uma postura cética dos estudantes acerca desta questão. Essa dinâmica é o foco e o objetivo central desta narrativa reflexiva.

Nosso objetivo é descrever com o máximo de detalhes possível, e dentro das limitações impostas pelo próprio ambiente escolar, essa experiência didática, que essencialmente se configurou no formato de uma espécie de júri simulado, que será detalhado oportunamente. Para tal, começamos fazendo uma breve exposição dos referenciais teórico e metodológico que servem como pano de fundo tanto para a utilização como para uma 
compreensão analítica da prática da argumentação e do desenvolvimento de pensamento crítico como ferramenta de aprendizado, bem como o quanto a autonomia intelectual do estudante pode e deve ser trabalhada em sala de aula com o objetivo de se alcançar uma educação científica virtuosa, competente e responsável, especialmente diante do quadro de mudanças marcantes do século XX que transformaram a sociedade do século XXI (comunicação de massa, urbanização, democratização do ensino, mudanças no mundo do trabalho, questões de gênero, infância e juventude, dentre outros), conforme chama a atenção, por exemplo, ROSSATO (2002).

\section{Referencial teórico e epistemológico}

A argumentação e os diversos usos da mesma, inclusive como ferramenta didática para a educação científica, é bastante utilizada, por exemplo, no contexto da Filosofia e do Direito, seja no domínio da lógica informal para a análise de argumentos em textos técnicos da área e em situações de colóquios em forma de questões disputadas (Quaestiones disputatae, bastante comum na Idade Média, como nas discussões acerca dos argumentos apresentados por São Tomás de Aquino na sua Suma Teológica, por exemplo, que eram debatidos nas universidades e também em praças públicas na época) e de júri simulado, ou em níveis mais avançados de estudos de Lógica formal nos cursos de graduação em Filosofia, embora com objetivos distintos em ambos os casos. Em contextos não necessariamente acadêmicos e escolares e em algumas situações da esfera e da vida pública, debates argumentativos são realizados em programas jornalísticos sobre os mais variados assuntos (por exemplo, versando sobre assuntos relacionados com temáticas políticas, o mais comum dos casos, dentre outros temas) de mesa redonda ou em outros formatos, com o objetivo de se avançar em alguma discussão através da dialogia orientada sempre se procurando oferecer razões e/ou outros elementos que procurem justificar as opiniões dos debatedores em questão. A estratégia do júri simulado também é um expediente bastante utilizado em atividades educativas que envolvam o uso da argumentação, e particularmente como ferramenta metodológica para o ensino de ciências, ela se mostra bastante útil e eficiente.

Autores como Stephen Toulmin e Peter Geach, em seus livros "Os Usos do Argumento" (TOULMIN, 2001) e "Razão e Argumentação" (GEACH, 2012), por exemplo, tratam dos diversos tipos de argumentação e dos seus usos, bem como analisam não apenas a estrutura lógica e formal dos argumentos e as técnicas de argumentação que podem e devem ser utilizadas em diversos contextos, mas também os elementos informais envolvidos, especialmente no que se refere a que tipos de elementos podem servir como critérios justificadores ao se passar das premissas para a conclusão em argumentos dedutivos, por exemplo, ou na melhor explicação e/ou no grau de certeza que probabiliza uma determinada conclusão provisória em argumentos indutivos e em raciocínios por indução, que, em geral, caracterizam boa parte das inferências realizadas para se construírem hipóteses, explicações e teorias científicas, especialmente no domínio das ciências da natureza. 
No domínio específico da argumentação na educação científica, Rosalind Driver e colaboradores (DRIVER; NEWTON; OSBORNE, 2000), além de outros autores que desenvolvem trabalhos e estudos na pesquisa em ensino de ciências como, por exemplo, Deanna Kuhn (KUHN, 1991, 1993, 2014) e outros (PLANTIN, 2014; SOLOMON, 1998; NASCIMENTO; VIEIRA, 2008) tratam da formulação teórica do estabelecimento de determinadas regras para a argumentação científica. Um ponto bastante comum entre os autores que trabalham com esta temática é a ênfase dada ao aspecto social na construção do conhecimento científico, e do quanto que uma abordagem de uma perspectiva CTS (Ciência, Tecnologia e Sociedade) que envolva questões de natureza sociocientíficas são importantes para o ensino de ciências. Driver (DRIVER, 2000) enfatiza que aspectos históricos e contextuais da ciência podem e devem ser utilizados a fim de se desenvolver habilidades e competências nos estudantes, como o uso da argumentação e do pensamento crítico como ferramentas para a aprendizagem, comparando a situação presente com questões do passado e ressignificando as mesmas para uma compreensão reflexiva destas no contexto atual. A referida autora, que é um nome de grande destaque na área da educação científica, também destaca a importância do ensino por argumentação concentrar-se no aspecto de uma educação sobre a ciência, e não apenas uma educação em ciência. Esta é uma distinção importante que será mais desenvolvida no presente estudo, haja vista que nela se concentram muitos aspectos sociais na construção do conhecimento científico, seu aspecto cada vez mais interdisciplinar, colaborativo, globalizado, marcado pela confiança no trabalho dos pares (FENSHAM, 2014) e as suas diversas implicações em sala de aula. Este é um tópico muito importante e relevante para esta pesquisa, onde a interface do ensino por argumentação como uma ferramenta para o letramento científico (assumido aqui como o conjunto de práticas cujo objetivo é promover uma formação que permita ao sujeito interagir com o mundo e o conhecimento dele (SASSERON; MACHADO, 2017)) em conexão com o desenvolvimento de habilidades e competências é fundamental para uma aprendizagem com sentido, como o desenvolvimento de pensamento crítico e de autonomia intelectual nos estudantes, entendidas estas aqui como virtudes epistêmicas neste processo todo. Todas estas são questões essenciais a serem trabalhadas com vistas ao aprimoramento deste referencial teórico e metodológico para um ensino de ciências virtuoso, reflexivo e responsável, como já comentado.

Uma das principais críticas que o ensino de ciências dito positivista mais sofre, por exemplo, é o da ausência do expediente discursivo nas práticas pedagógicas, onde o suposto processo de ensino-aprendizagem está concentrado na memorização de conteúdos (e na exposição excessiva destes, de forma unidirecional, pelo professor), não permitindo que o estudante pense e reflita sobre aquilo que está aprendendo, ficando o seu julgamento crítico, com isso, bastante prejudicado, e não havendo propriamente uma compreensão, um entendimento (understanding) sobre o tema em questão. É exatamente neste ponto que a ferramenta da argumentação como instrumento didático entra, pois ela permite que o estudante formule as questões e concatene o seu raciocínio mediante a formação de juízos 
reflexivos e pensamento crítico, construindo argumentos, sejam eles dedutivos ou indutivos, a fim de se obter conhecimento científico e aprendizado reflexivo e crítico acerca deste conhecimento adquirido. $\mathrm{Na}$ interface da literatura entre uma epistemologia do conhecimento científico centrada no desenvolvimento de virtudes epistêmicas e intelectuais com uma educação científica virtuosa, cidadã e responsável, o debate entre as epistemologias de Alvin Goldman e Harvey Siegel faz-se bastante pertinente e relevante a fim de ilustrar a problemática que se coloca para o ensino de ciências entre o conhecimento proposicional como o valor mais importante a fim de se obter aprendizado, ou se o objetivo final de uma educação científica virtuosa deva ser o desenvolvimento de determinadas habilidades cognitivas no aluno (pensamento crítico, capacidade de argumentação, possibilidade de colocar-se como agente transformador do processo de ensino-aprendizagem): nesse sentido, os trabalhos de Siegel e Smith \& Siegel (SIEGEL, 2005 e SMITH; SIEGEL, 2004), por exemplo, tratam essencialmente deste debate e das controvérsias advindas daí.

Goldman, na sua epistemologia, que é essencialmente social nas suas bases (GOLDMAN, 1999), confere ao testemunho um papel muito importante na aquisição e transmissão do conhecimento, com a sua teoria externalista do confiabilismo epistêmico, onde é condição necessária para o receptor da informação que este atribua alguma confiabilidade ao transmissor da informação veiculada como crença não acidentalmente verdadeira: é através do testemunho do professor, por exemplo, que o aluno, no mais das vezes, na perspectiva de Goldman, adquire conhecimento, pois este confia no testemunho das informações passadas pelo professor em sala de aula. Já Siegel contrapõe, em parte, esta concepção, não colocando como valor máximo no processo educacional o papel do testemunho do professor e da confiança que o aluno deposita no mesmo como um fator determinante e decisivo para se efetivar o aprendizado: Siegel, assim como para outros autores que são mais radicais nesta interpretação (como, por exemplo, BAHER, 2014; HODSON, 2004), defende um modelo para a educação científica baseado em questões sociocientíficas para uma aprendizagem para a vida, que desenvolva no aluno autonomia e senso de cidadania. Este autor argumenta que é mais importante que o aluno seja um agente ativo nesse processo, e não apenas um receptor passivo que tome dogmaticamente as crenças do professor como verdades absolutas e irrefutáveis sem ser capaz de refletir criticamente sobre as mesmas. Essa agência epistêmica de que fala Siegel concentra-se em uma ideia construtivista de ensino, onde o aprendizado do aluno se dá por mérito e esforço dele não apenas do ponto de vista cognitivo, ele conquistou o aprendizado mediante o exercício de virtudes epistêmicas e intelectuais, desenvolvendo pensamento e capacidade crítica sobre o tema em questão, sendo capaz de aprender através do exercício de práticas argumentativas como a dialogia orientada e do fornecimento de explicações tanto sobre conceitos quanto da prática propriamente científica advindas da reflexão e do senso crítico que orienta a sua práxis em direção à aquisição de um aprendizado significativo para a formação de um sujeito conhecedor e também resolvedor de problemas no seu dia a dia. 
Nas perspectivas de Hodson e Baher, há alguns níveis metodológicos que devem ser seguidos no seu modelo, cuja estrutura subjacente é a de uma profunda reformulação curricular dentro do ensino de ciências: dentre estes níveis, há que se ter o reconhecimento de que os impactos sociais das mudanças científicas e tecnológicas são culturalmente determinados e, basicamente, que aspectos políticos e subjetivos são inerentes e indissociáveis à prática científica, que é o último nível em que efetivamente se dará a práxis, a ação propriamente dita neste processo todo. Uma educação para as virtudes estaria centrada nesta visão, superando uma espécie de dualismo que existiria no ensino de ciências entre o valor do conhecimento e o valor do entendimento, que é uma posição que é, de certa forma, endossada por Goldman e também por Siegel, pois ambos consideram os dois aspectos, o do conhecimento e o do entendimento, nas suas epistemologias da virtude aplicadas à educação científica: nos primeiros níveis, as capacidades do entendimento enquanto critical thinking são desenvolvidas, ao passo que para além da autonomia intelectual, como a ação política e participativa do aluno na sociedade estão em um nível onde uma educação para as virtudes é exercida plenamente e o aluno é visto como um agente epistêmico transformador.

$\mathrm{Na}$ perspectiva deste referencial e em conexão com o mesmo, a presença da argumentação em sala de aula pode e deve ser um instrumento de aprendizagem poderoso se for compreendida como uma metodologia que se aproxime e se identifique com uma virtude intelectual. Esta argumentação é dialógica e comunicacional no contexto da educação científica, em particular aqui do ensino de Física, em que o debate e/ou júri simulado promovam pensamento crítico e, através deste, a formulação de raciocínios revisáveis em que seja possível rever as conclusões obtidas e mesmo modificá-las, e com isto avançar em direção a uma educação científica virtuosa, responsável e reflexiva. No micromódulo de ensino aqui descrito, cujas bases teóricas e metodológicas procuraram se fundamentar nestes referenciais como base de apoio e estofo conceitual, as atividades propostas tiveram sempre este horizonte em sua perspectiva, a saber, a obtenção de alguma espécie de aprendizado advindo dos debates e do júri simulado, concatenado com explicações sobre conceitos básicos de Física e de Astronomia que auxiliassem os estudantes no desenvolvimento das suas explicações e dos seus argumentos sobre os tópicos em questão.

Em relação ao padrão de argumentação de Stephen Toulmin (1958), suas ideias oferecem uma caracterização prescritiva sobre a argumentação, em uma análise de argumentos de uma forma não apenas monológica, mas também dialógica e com biunivocidade de significados, a partir de elementos lógicos básicos. Quando isto é aplicado à educação científica, como chamam a atenção vários autores já referidos anteriormente e que trabalham, direta ou indiretamente, com esta temática (DRIVER; NEWTON; OSBORNE, 2000; KUHN, 1991, 1993, 2014; PLANTIN, 2005; SOLOMON, 1998), alguma espécie de aprendizado pode e mesmo deve derivar daí, tanto como consequência de resultados de estudos de caso empíricos, ou como reflexões gerais, especialmente sob o aspecto epistemológico, a partir deste referencial teórico aplicado à educação de ciências. Sem 
aprofundar muito sobre os aspectos conceituais da teoria da argumentação toulminiana, que é bastante complexa e exigiria longos parágrafos para detalhamento para sua plena compreensão, basicamente o que temos na estrutura argumentativa do assim chamado "padrão de Toulmin", especificamente no presente contexto de sala de aula, é a presença de premissas e conclusões no argumento. Em outras palavras, a partir dos elementos que compõem as premissas, que Toulmin chama de "dados", se inferem dedutivamente a conclusão ou conclusões do argumento, e as garantias, o apoio, que Toulmin chama de "qualificadores modais", são os fatores que justificam estas conclusões, tornando a passagem "Se P, então Q" (de implicação lógica) uma passagem logicamente legítima, onde $\mathrm{P}$ é o conjunto de premissas, e Q a conclusão. É importante destacar que, analogamente, se pode tornar ilegítima ou mesmo inválida esta passagem, através de fatores que refutem ou anulem a conclusão Q a partir da(s) premissa(s) P. Uma vez que estes elementos sejam minimamente aplicados em módulos de ensino que façam uso desta metodologia do ensino por argumentação, utilizando este modelo, há boas razões para crer, baseadas no modelo, que se atinja uma aprendizagem a partir de uma reflexão crítica e autônoma por parte do estudante.

Também há nas Diretrizes Curriculares Nacionais para a Educação Básica (DCNEB) (BRASIL, 2013) e na Base Nacional Comum Curricular (BNCC) (BRASIL, 2018) este indicativo ao pensamento crítico no âmbito da educação científica, advindo de processos argumentativos em sala de aula, particularmente no nosso caso do ensino de Física e de Ciências Naturais, tomados como competências e habilidades previstas no desenvolvimento cognitivo do aluno. Os documentos colocam que atingir esta meta é não só um dever da educação científica, como um direito e um dever do aluno almejar atingir esta condição no âmbito de uma educação voltada à formação cidadã.

Na próxima seção será feita uma breve descrição da experiência didática realizada, contextualizando-a dentro do universo da escola pública em que foi executada, com todos os aspectos e idiossincrasias da mesma, e algumas questões e reflexões serão suscitadas e promovidas a fim de se detalhar mais o estudo de caso, cujas bases teóricas e metodológicas que o inspiraram e o promoveram foram, de forma muito breve e resumida, expostas e analisadas nesta seção. Apesar das menções a outros referenciais aqui expostos, com a finalidade, também, de mapear e situar o estado da arte que norteia, em alguma medida, o ensino de ciências por investigação, o padrão de argumentação de Toulmin será essencialmente a metodologia utilizada neste trabalho. Esta se justifica por sua relevância na dinâmica do micromódulo, se esperando obter a partir daí aprendizado através de discussões críticas e revisáveis. A menção aos outros referenciais aqui citados, contudo, não é menos importante, especialmente em relação ao desenvolvimento do pensamento crítico e da autonomia no estudante, elementos estes centrais para uma educação científica virtuosa e formadora de sujeitos reflexivos e participativos na sociedade. 


\section{O contexto da experiência didática: descrição geral e algumas observações e reflexões sobre o debate argumentativo em sala de aula}

A metodologia utilizada consistiu na seguinte dinâmica de grupo: 1) contato prévio com material de estudo e de divulgação sobre o tema (matérias de divulgação científica selecionadas em jornais, artigos e periódicos sobre o tema, vídeos e programas de televisão, entrevistas, etc.), cujo objetivo visava a preparação do debate; 2) organização dos estudantes em três grandes grupos para fazer a discussão, a saber: o grupo dos defensores da ida do homem à Lua (e consequentemente do sucesso das Missões Apollo, especialmente a Apollo 11), o grupo daqueles que negavam tal feito (os defensores da teoria da conspiração sobre este tema), e o grupo dos céticos, que suspende o juízo sobre a ida do homem à Lua, nem negando nem afirmando tal feito (suspende o juízo mediante "boas" razões e/ou evidências para tanto); 3) desenvolvimento, em si, do debate argumentativo. Destaca-se que a escolha das posições foi feita pelo professor/pesquisador proponente da pesquisa para o projeto-piloto, e os estudantes agruparam-se por afinidade com as suas posições pessoais.

Os materiais utilizados foram os seguintes: vídeos do Youtube

(https://www.youtube.com/watch?v=r_qwxl-4Cow\&t=162s e

https://www.youtube.com/watch?v=vyPzUt1yzCg);

textos de apoio do Centro de Referência para o Estudo de Física (CREF-IF/UFRGS) (https://www.if.ufrgs.br/novocref/?contact-pergunta=sombras-nao-paralelas-nas-fotos-dasmissoes-apollo-seriam-as-fotos-falsas) e matérias e reportagens científicas de jornais e revistas, além de outras fontes (site da NASA e de outras instituições de ensino e de pesquisa científicas).

Participaram da atividade aproximadamente 25 estudantes de uma turma de segundo ano de uma escola pública de Porto Alegre, igualmente distribuídos entre meninas e meninos com idades entre 15 e 17 anos e o micromódulo foi aplicado no período de 14/11/2018 a 05/12/2018, ao longo de seis encontros.

A seguir, faz-se um breve relato dos principais pontos e questões surgidas do debate, com transcrições aproximadas das discussões suscitadas por perguntas feitas para os três grupos a fim de dar início à dialogia orientada em formato de júri simulado, onde o papel do professor/pesquisador proponente foi o de fazer a mediação da discussão.

Os três grupos organizaram-se espacialmente da seguinte forma: na parte direita da sala, ficou localizado o grupo dos negacionistas, ou defensores da posição de que a Missão Apollo fez parte de uma teoria da conspiração para enganar e manipular a opinião pública (aproximadamente 6 alunos); no meio da sala posicionou-se o grupo majoritário, o dos céticos, com aproximadamente 15 alunos; na parte esquerda, o grupo dos que acreditam que a Missão Apollo aconteceu e de que o homem de fato foi à Lua (aproximadamente 5 alunos). Para iniciar a discussão, foi lançada a seguinte pergunta: se o homem foi à Lua, então porque a bandeira fincada no solo lunar pelo astronauta Neil Armstrong parece tremular, já que não existe atmosfera no satélite natural da Terra? O grupo da esquerda argumentou, baseado em 
informação contida em um dos vídeos assistidos do material didático disponível, e também nos textos fornecidos para estudo prévio, que tal efeito não era causado pela presença do vento, que não poderia ser gerado em um ambiente sem atmosfera, e sim pelo fato da bandeira ter sido desenrolada do invólucro em que estava antes de ser hasteada e enterrada, dando a impressão de que parecia estar tremulando. O grupo da direita procurou rebater este argumento defendendo a hipótese de que o fato da bandeira parecer tremular seria uma evidência de que os supostos "astronautas" a fincaram na Terra, em um deserto localizado no interior dos EUA, onde haveria a presença de vento. O grupo dos céticos suspendeu o juízo entre uma explicação e outra, alegando não haverem elementos suficientes para poder se decidir entre uma posição e outra, ou seja, eles alegaram que não seria possível, de posse das evidências disponíveis, escolher entre uma das duas alternativas. Basicamente, o debate acerca desta controvérsia girou em torno desta questão.

Dando continuidade ao júri simulado, foi lançada uma segunda pergunta sobre a questão das sombras paralelas: um aluno do grupo da esquerda, chamado aqui pelo nome fictíco de Ricardo, demonstrou bastante desenvoltura ao mostrar, de modo bem argumentado, que o fato de aparecerem sombras não paralelas não significava necessariamente que haveria mais de uma fonte de luz presente, pois, de acordo com o material disponibilizado (textos do CREF do Prof. Fernando Lang sobre Óptica Geométrica, dentre outras fontes, conforme referências anteriores), as sombras projetadas se encontram no infinito; Ricardo pareceu compreender esta ideia, apesar do alto índice de abstração da mesma, mesmo sem ter estudado conteúdos de óptica na escola ainda, e também argumentou que as irregularidades do terreno lunar, pouco conhecidas, distorceriam visualmente as sombras, dando a impressão de que não seriam paralelas (efeito da ilusão de óptica, que apesar dele não conhecer do ponto de vista do ensino formal, pareceu compreender, pelo menos, como "pano de fundo" teórico para a discussão). O grupo da direita, liderado pelos alunos Vinícius e Roger (também nomes fictícios), procurou contrapor a questão do não paralelismo das sombras apelando para a mesma argumentação do caso anterior, ou seja, a da teoria da conspiração, focando na explicação de que o que melhor descreveria este fenômeno seria a presença de outras fontes de luz no ambiente, como câmeras de vídeos registrando a gravação em um suposto "set de filmagem" que serviria de cenário para o "filme" sobre a ida do homem à Lua. O grupo dos céticos, sempre com o aluno Wesley tomando a iniciativa e a palavra, novamente suspendeu o juízo baseado na mesma argumentação de que não haveria elementos suficientes para se decidir entre uma posição e outra. É importante destacar que aparentemente o grupo dos céticos, de um modo geral, não pareceu demonstrar compreensão plena do real significado do que estava em jogo. Na sequência do debate, a título meramente ilustrativo para exemplificar o contexto da discussão que estava sendo empreendida, foi referido pelo mediador o método para medir-se a distância entre a Terra e a Lua através de espelhos refletores colocados pelos astronautas na superfície lunar. O grupo dos negacionistas, endossado também pelos céticos, que tinha também a função de ser uma espécie de "juiz" no debate do júri simulado, procurou 
mostrar que era falsa tal alegação argumentando que não seria necessário realizar um experimento com esta finalidade, pois se assim o fosse, para determinar a distância entre o Sol e a Terra, por exemplo, então teria que se instalar os mesmos espelhos na superfície do Sol, o que obviamente não foi feito e nem o poderia ser, por razões conhecidas. O grupo dos defensores da ida à Lua argumentou que este era um bom método para fazer tal estimativa, mas reconheceu também que não seria necessário instalar os espelhos lá para fazer a medida, mas também consideraram tal hipótese plausível e coerente com as suas crenças de que o homem foi à Lua (isto é, consideraram plausível e razoável a instalação de espelhos na Lua com esta finalidade).

Também foram levantadas e discutidas as marcas das pegadas dos astronautas em solo lunar e da aterrisagem e alunissagem do módulo lunar levantando poeira na superfície, o que poderia ser uma evidência da existência de alguma atmosfera no ambiente. $O$ grupo dos negacionistas, pela voz dos alunos Vinícius e Roger especialmente, utilizou o mesmo argumento das situações anteriores, a saber, de que o cenário era o de um deserto no interior do território estadunidense norte-americano, e que as marcas das pegadas seriam devido à umidade do solo, mesmo sendo um deserto (o aluno Roger citou inclusive as elevadas variações de temperatura que os desertos terrestres geralmente sofrem, com altas temperaturas e calor durante o dia, e temperaturas baixas e frio durante a noite) e que a elevação da poeira era devido ao vento do deserto, o tal cenário para o estúdio cinematográfico. No grupo da esquerda, os defensores da ida do ser humano à Lua, também sempre liderado pelo aluno Ricardo, contra-argumentou que a marca da pegada poderia ter sido feita e não seria mais desfeita devido à ausência da atmosfera e do vento; o grupo utilizou a analogia mostrada em vídeo apresentado em aula das marcas que ficariam gravadas no pó de maquiagem e rímel, semelhantes à composição da areia do solo lunar, que mesmo secas, gravariam e manteriam os detalhes das marcas, e que o efeito da aterrissagem e alunissagem não era devido ao vento. Os céticos declararam que ambas as explicações não seriam suficientes para se decidir entre uma posição ou outra, mas o aluno Wesley, sempre atento e interessado, que no mais das vezes fez a voz das opiniões/crenças do grupo dos céticos (por muitas vezes confundidas com a sua própria visão) disse ter ficado bastante inclinado a aceitar os argumentos do grupo dos defensores da ida à Lua, mas que ainda assim mantinha suas dúvidas, pois não estaria totalmente convencido.

Também a questão da ausência das estrelas nas fotos foi ressaltada pelos negacionistas como evidência da "farsa" da ida do ser humano à Lua, usando o argumento de que o estúdio no deserto era fechado, e por isso não se enxergava nenhuma estrela. Os defensores da ida à Lua, grupo da esquerda, argumentaram que os astronautas não estavam preocupados em registrar o céu estrelado, e fotografaram o que era mais interessante para os propósitos da missão, mantendo também a abertura do obturador das câmeras por pouco tempo aberta, assim como a luminosidade dos flashs, o que explicaria, em parte, o céu escuro; citaram também a dificuldade com a tecnologia atual de se obter com as câmeras de 
smartphones um céu estrelado, e que isso seria uma boa explicação para a escuridão noturna lunar, já que as câmeras fotográficas da época eram muito rudimentares frente às atuais e que esta tecnologia não ajudava muito neste quesito (além do aluno Ricardo, o aluno Moisés também destacou esses detalhes). Os céticos endossaram essa posição, e inclinaram-se para o grupo da esquerda nesta questão em específico.

$\mathrm{Na}$ sequência, foi levantada a questão de haver fotos da Apollo 11 saindo da Lua: quem as teria tirado, se todos os astronautas estavam a bordo para partirem de lá? Os negacionistas disseram que esta seria mais uma evidência de que houve uma fraude, pois a foto teria sido feita por alguém que estava participando das "filmagens"; os céticos também endossaram esse ponto de vista, e o grupo da esquerda argumentou que essa não era uma boa explicação, pois os astronautas deixaram uma câmera em solo lunar e foi ela que registrou a saída. Os negacionistas e os céticos disseram que com a tecnologia "não digital" disponível na época, teria sido impossível fazer isso, e isso não seria uma prova convincente de que o ser humano foi à Lua. Em torno desta e de outras questões suscitadas, um detalhe bastante interessante e curioso que permeou boa parte da argumentação utilizada pelo grupo dos negacionistas foi o da tecnologia da época, que não poderia permitir que viagens ao espaço fossem realizadas com o que se tinha disponível, tanto do ponto de vista científico, com a ciência da época, quanto tecnológico, mas que para fazer um filme, uma encenação de tudo, que era o que estavam defendendo, isso seria muito mais plausível e "razoável": por extensão, com esse raciocínio tais grupos estavam negando também todo o contexto da corrida espacial da década de 1950 (URSS versus EUA) e todos os seus desdobramentos e consequências para as missões presentes e futuras projetadas e realizadas, sejam elas tripuladas ou não. Para os defensores da ida à Lua e para o grupo dos céticos, estes argumentos obviamente não se sustentam, e eles defenderam com bastante veemência os avanços científicos e tecnológicos ao longo das décadas da segunda metade do século XX que corroboravam esta posição. De forma bastante breve e resumida, estas foram as considerações gerais surgidas no debate, que no fim das contas, ao menos provisoriamente, apresentou as evidências de ambos os lados e as suas respectivas defesas, e não se chegou a uma conclusão definitiva, baseando-se nos argumentos apresentados, deixando a questão em aberto, o que era um dos objetivos previstos e que foi alcançado, ao menos parcialmente.

Em conversa posterior ao debate com os alunos (no dia 06/12/2018), foi perguntado quais pontos e questões que eles haviam aprovado na atividade, e quais teriam reprovado ou não teriam gostado. Uma das particularidades que eles fizeram questão de relatar sobre a experiência foi que muitos dos integrantes do grupo dos céticos sentiram falta da presença de um espaço maior para discussão, eles se sentiram um tanto deslocados na dinâmica do júri simulado, pois não sabiam e/ou não conseguiam expor de maneira clara as suas posições e convicções. De um modo geral, pareceu que eles confundiram posição cética e suspensão de juízo com uma postura do tipo "não irei me manifestar, já que não possuo opinião"; falta de opinião, ou de uma opinião fundamentada e abalizada por evidências e razões, foi tomado 
como sinônimo de uma postura cética. Além disso, eles alegaram que o debate ficou "polarizado" demais, muito concentrado nos grupos defensores da ida à Lua versus negacionistas e eles, céticos, sentiram-se um tanto alijados e excluídos das discussões de uma maneira geral (algumas considerações acerca destas questões serão comentadas e discutidas posteriormente, na próxima seção).

No mais, aprovaram a dinâmica argumentativa da atividade de debate, e pareceram reconhecer nela algum instrumento capaz de desenvolver algum tipo de aprendizado sobre o tema/matéria em questão. $\mathrm{O}$ assunto da credibilidade na ciência e nas teorias científicas de maneira geral acabou surgindo como complemento às discussões realizadas, no sentido de se enfatizar e investigar de por quais razões o conhecimento científico sofre tanto, de um lado, de descrédito na sociedade em nome de uma visão de senso comum, posição esta oposta e contrária ao que uma educação científica virtuosa e cidadã deve se preocupar em atingir, como está expresso, por exemplo, nas DCNEB e também na BNCC, documentos públicos antes referidos e que tratam das habilidades e competências que precisam ser desenvolvidas nos estudantes.

Outra questão interessante que surgiu nessa conversa foi das razões que motivaram o abandono do projeto de exploração à Lua da Missão Apollo pela NASA: alguns alunos questionaram o porquê do projeto ter sido abandonado, se por mero desinteresse, falta de verbas, etc., e argumentaram que isto daria margem para um descrédito geral, motivando as teorias da conspiração elaboradas sobre o tema. Ao final da conversa, a despeito dos pontos negativos da dinâmica do debate apontados e criticados por alguns alunos e outras questões, o saldo final foi positivo, mostrando que atividades desta natureza, como o júri simulado (STUPMF; OLIVEIRA, 2016; SILVA; MARTINS, 2009; GOMES; BARBOZA, 2013, apenas para citar alguns exemplos de trabalhos no ensino de ciências que se utilizam desta metodologia) e o debate argumentativo, elaboradas com mais detalhe e com mais tempo para desenvolver mais profundamente as questões, podem render mais frutos, com resultados interessantes, relevantes e significativos visando uma aprendizagem que vá além da mera aula tradicional conteudista e explanatória, forçando o aluno a sair da sua condição de agente passivo no processo pedagógico, tornando-o um agente ativo, crítico e autônomo, com capacidade reflexiva sobre o tema em questão e senso crítico para bem avaliar os conteúdos e as explicações e construir o conhecimento em conjunto, tanto com seus colegas, quanto com o professor mediador. O processo ensino-aprendizagem de ciências, além do seu aspecto cognitivista individual e de grupo, torna-se também socialmente construído, quando motivado e gerado pelo processo da argumentação dialógica.

\section{Estudo de Caso: uma breve análise sobre os dados do micromódulo de ensino, algumas reflexões e considerações finais}

A fim de se proceder por uma análise dos dados recolhidos durante a aplicação do micromódulo, foi solicitado aos alunos que elaborassem pequenas redações, de no máximo 
uma ou duas páginas, acerca das suas posições sobre a Missão Apollo e a chegada do ser humano à Lua. As respostas deveriam estar baseadas no material de apoio disponibilizado a eles e também nas opiniões fundamentadas no debate, permitindo com isso que se construíssem textos argumentativos e se apresentassem as razões pelas quais eles defendiam a posição $\mathrm{X}$ ou $\mathrm{Y}$, por exemplo. $\mathrm{O}$ objetivo dessa atividade era, além do fornecimento de uma base teórica, possibilitar o embasamento das suas respostas em consonância com o debate/júri simulado e as outras atividades que foram realizadas em sala de aula. Esta análise preliminar, haja vista que outros módulos serão aplicados utilizando-se a metodologia da argumentação, esteve espelhada particularmente no modelo qualitativo de categorização que Santos, Mortimer e Scott (2001) utilizaram em um estudo de caso que realizaram e que está relatado em artigo, em que foi utilizado uma ferramenta de análise desenvolvida pelos autores, denominada de framework analítico, que faz uso das diferentes vozes e perspectivas existentes no ambiente escolar para realizar uma análise do discurso em sala de aula, e tomando como base teórica o trabalho de N. Mercer, The guided construction of knowledge, de 1995, cujo objetivo consiste em organizar minimamente estes dados a fim de se trazer algum esclarecimento dos mesmos à luz destes referenciais adotados.

Basicamente se procurou criar, tendo estes trabalhos como referência, algumas categorias que sistematizem esta análise; categorias centradas, por exemplo, na participação dos alunos, na organização do debate realizado em sala de aula e nas respostas dos alunos acerca das questões que motivaram e suscitaram o debate. De maneira geral, no presente caso foi tomado muito mais tempo na organização do debate, como a separação dos grupos e a explicação de como a atividade funcionaria e a sua importância, do que o estímulo à participação dos alunos e o fornecimento de respostas aos mesmos: antes mesmo do debate propriamente iniciar-se, uma explicação de como o mesmo funcionaria em sua dinâmica, juntamente com uma motivação extra para a classe participar e se engajar, foi uma condição necessária para a realização e o êxito do mesmo. Procurando-se quantificar minimamente estas categorizações, pode-se dizer que em torno de aproximadamente $65 \%$ do tempo dedicado à atividade dividiu-se entre a organização e a provocação pela participação dos alunos, e apenas uns $35 \%$ do tempo total foi utilizado no desenvolvimento da atividade e para responder aos alunos sobre os questionamentos levantados durante o debate. Se dispuséssemos de mais tempo, com um módulo mais extenso, estes números poderiam e mesmo deveriam ter sido diferentes. O elemento tempo é um fator importante para propiciar aos alunos maior contato com os textos, aprofundando assuntos trabalhados, gerando, com isso, de forma mais natural e espontânea um aumento do engajamento e da motivação nos mesmos.

Em termos de uma análise das respostas das redações entregues pelos alunos, um total de 14 foi feito respeitando os grupos em que eles se dividiram: a maioria preferiu escrever em pequenos subgrupos dentro dos três grandes grupos em que foi realizada a atividade, e uma minoria escreveu a redação sozinha, de forma independente, embora a 
discussão tenha sido feita no grande grupo. Os resultados quantitativos, em termos percentuais, foram bastante divididos em relação à tomada de posição da turma sobre a questão, e diferem um pouco das posições alegadas durante o debate, não havendo uma total coincidência destas com as respostas redigidas: aproximadamente $30 \%$, um pouco menos (28,5\%), alegaram nas respostas escritas que o ser humano foi à Lua, o mesmo número e percentual foi observado para os negacionistas, totalizando $57 \%$ (oito redações do total das 14); as seis redações restantes endossam a posição cética da suspensão do juízo, totalizando aproximadamente $43 \%$ do total. Pela análise dos dados, a maioria defende a posição oficial de que o ser humano foi à Lua e a contrária, de que o ser humano não foi (ou seja, escolheram um lado que não o dos céticos), e um pouco menos da metade adota a postura cética da suspensão do juízo, o que difere um pouco da configuração dos grupos, onde o grupo dos céticos era o de maior número em sala de aula. Apesar desta pequena diferença, pode-se afirmar que o resultado final não muda muito, pois a posição cética, sozinha, ainda é a dominante, mas por uma margem não tão significativa. Tanto na defesa dos argumentos e das alegações céticas quanto os da ida e da não ida do ser humano à Lua, os alunos procuraram sustentar as suas razões no corpo de evidências que foram apresentadas durante a realização da atividade do micromódulo de ensino, a saber, a questão de a bandeira estar de fato tremulando, ou apenas parecer que está em movimento na superfície lunar; as pegadas dos astronautas, filmagens deles caminhando no solo da Lua; a ausência de estrelas no céu; o paralelismo ou não das sombras projetadas pelos objetos em solo lunar e a existência (ou não) de tecnologia aeroespacial suficiente para levar o homem à Lua, além dos avanços científicos e tecnológicos conquistados pelos EUA e pela URSS durante as décadas de 1950, 1960 e 1970 em seus programas espaciais, a fim de empreenderem a supremacia de um sobre o outro no contexto geopolítico e econômico dominante na época.

Refletindo um pouco sobre a breve análise de dados do presente estudo de caso, apesar da pouca quantidade dos mesmos em vista do módulo ter tido curta duração, podem-se levantar algumas questões para reflexão posterior, seja para uma reaplicação do micromódulo em algum momento posterior, com mais tempo em sala de aula, ou mesmo como especulação meramente teórica e conceitual $\mathrm{O}$ dado que mais chama a atenção é a significativa presença da atitude cética na avaliação dos estudantes. Podemos arriscar algumas explicações para isso: tal "ceticismo", de um modo geral (com algumas exceções, como no caso do aluno Wesley, por exemplo, que conforme já dito anteriormente, procurava justificar com algum rigor argumentativo as suas alegações) parece ser derivado mais do desconhecimento e também de certo desinteresse pelo assunto do que propriamente uma suspensão do juízo fundamentada em desacordos racionais que levassem os indivíduos a esta condição, no sentido de se pesarem tanto razões favoráveis a uma determinada proposição $\mathrm{P}$ qualquer e não favoráveis a $\mathrm{P}$, onde a atitude mais razoável nestes casos seria a suspensão de juízo, neste caso genuinamente cética, do ponto de vista epistêmico. Quando os estudantes do grupo dos negacionistas, embora minoritário, defendeu o seu ponto de vista, tal atitude pareceu mais 
convicta e propositiva do que a do grupo dos céticos, pois estes procuraram apresentar e justificar mais as suas razões do que os céticos.

Aqui podemos tangenciar um aspecto interessante, especulando sobre estas questões, que é o quanto que o elemento motivacional e o comprometimento do estudante com o ponto de vista que ele considera, de fato, o mais razoável para defender na sua argumentação é importante para que haja alguma espécie de aprendizado no processo argumentativo: a capacidade do entendimento e da compreensão discutida na seção do referencial teórico e epistemológico parece, pelo menos potencialmente, desempenhar um papel crucial aqui, pois o cenário é favorável para que isto, em alguma medida, se dê na prática, emergindo dos debates dialógicos de uma forma não óbvia e evidente, se requerendo, assim, um olhar mais atento do pesquisador em ensino de ciências e do professor que está conduzindo a atividade e estudando os seus impactos na educação científica. É com este espírito de comprometimento e envolvimento com a atividade através do debate argumentativo, que se esperava, por exemplo, que tanto o grupo dos defensores da ida do ser humano à Lua através da Missão Apollo, quanto o grupo dos céticos se engajassem mais, tanto no estudo e na preparação para a atividade quanto no debate propriamente dito, cujo objetivo era, de fato, permitir um espaço de fala e de ação para o aluno que se desvinculasse, em grande medida, do modelo de aula tradicional conteudista (com o professor expondo a matéria e os alunos passivamente recebendo as informações, como já apontado).

A atitude mais propositiva acabou advindo mais do grupo dos negacionistas, pois estes pareceram talvez "captar" mais esse espírito da atividade e, embora não fossem maioria na turma, pode-se dizer, em alguma medida, que acabaram dominando e "vencendo" o debate, pois justamente foram mais veementes nos seus argumentos, embora os mesmos não possam ser, de forma racional e consistente, defendidos com pretensões de boa justificação de proposições científicas no âmbito de uma divulgação científica séria, responsável e comprometida com o que a comunidade endossa e produz. $\mathrm{O}$ "vencer" aqui mencionado está muito mais relacionado com a atitude propositiva, de engajamento e participação ativa no debate, do que propriamente com o juízo de valor de ter ou não razão e de ser logicamente consistente e coerente diante dos argumentos apresentados.

Assim, usando o padrão de argumentação de Toulmin referido anteriormente, por exemplo, para tentar analisar minimamente os argumentos produzidos pelos estudantes neste micromódulo, com todas as limitações de tempo para trabalhar com mais detalhe e refinamento o conteúdo e as práticas do debate/júri simulado, podemos constatar que no caso do grupo dos céticos, pareceu que estes souberam utilizar, mesmo que sem o conhecimento pleno dos usos do argumento feito por Stephen Toulmin, o seu padrão de argumentação, pois o que levou boa parte dos estudantes defensores desta posição a terem a atitude da suspensão do juízo acerca da ida ou não do homem à Lua foi uma análise das evidências disponíveis à luz deste referencial, ou seja, essa suspensão do juízo deu-se após uma espécie de cálculo racional destas evidências, tanto a favor ou não da factividade da Missão Apollo: se esta é a 
melhor das explicações a partir desta análise é uma outra discussão, a qual não pretendemos entrar no mérito aqui, pois isto envolveria um juízo de valor que, na condição de pesquisadores e condutores do estudo, tentamos buscar o máximo de isenção e neutralidade, por mais que isto seja difícil e, no fim das contas, quase impossível de conseguir, pois quem está envolvido no estudo nesta condição, inevitavelmente carrega consigo determinados pressupostos teóricos e espera resultados compatíveis e condizentes com os mesmos, o que de certa forma é uma tendência natural. Ou seja, a postura cética, que filosófica e logicamente é uma postura de racionalidade diante das evidências apresentadas, é um resultado que pode advir de um debate orientado cuja análise é realizada através de um padrão de argumentação toulminiano, pois se ponderaram e se consideraram as possibilidades, sendo a suspensão de juízo uma atitude derivada deste exercício intelectual e não um mero "achismo" sem justificação para as opiniões dadas. No caso dos critérios utilizados pelo grupo dos negacionistas e pelos defensores da ida do ser humano à Lua, pode-se dizer também que minimamente houve a utilização de critérios justificadores, tanto para justificar certas conclusões como para refutar outras. O caso da utilização das leis da ótica geométrica como um elemento que explicasse a razão do não paralelismo das sombras em favor dos defensores da Missão Apollo parece ser um ótimo exemplo disso, pois foram utilizados fundamentos de uma teoria física aceita pela comunidade científica a fim de explicar um fenômeno sob este viés, e não apenas por uma visão ingênua de senso comum que pode levar ao erro, formando a partir daí um juízo equivocado, e refutando, com isso, essa visão errônea baseada nestes critérios, o que novamente vem a mostrar, em alguma medida, a presença de um elemento de argumentação no padrão toulminiano.

É importante ressaltar o que seja a noção de cogência em um argumento, isto é, a passagem de premissas verdadeiras para uma conclusão igualmente verdadeira: para a lógica, e para Toulmin também, o argumento mais forte é o cogente, pois a verdade é transmitida das premissas para a conclusão, e isto é o que se deseja em diversos contextos argumentativos, em especial na argumentação científica, e quando hipóteses, resultados de experimentos e teorias científicas são utilizados como elementos justificadores para esta transmissão, o nível de confiança e de eficácia do argumento aumenta, tornando-o mais sólido e eficiente. No caso anterior, verifica-se isto, e mesmo no caso de algumas explicações dos negacionistas, como, por exemplo, a do estúdio cinematográfico, onde o ambiente seria um deserto em algum lugar na Terra e não a superfície da Lua, e o vento é que faria a bandeira tremular, embora possa não haver cogência, pois as premissas e conclusões podem não ser verdadeiras, há coerência no raciocínio (mesmo sendo as premissas e conclusões falsas), e isto dentro do exercício argumentativo é um recurso válido e deve ser considerado para fins persuasivos e retóricos, por exemplo; se há aprendizagem propriamente nestas situações é uma discussão interessante e que pode e deve ser feita com mais detalhe em outro momento, mas a mera reflexão sobre isto neste contexto já é suficiente para motivar e pensar a respeito deste tópico extremamente importante. O problema a ser evitado na argumentação, em qualquer nível e contexto, é 
quando o raciocínio é falacioso, seja em falácias formais ou informais válidas (premissas falsas e conclusões verdadeiras) e inválidas (premissas verdadeiras e conclusões falsas), pois aí temos problemas na forma de raciocinar, e nestes casos certamente não haverá aprendizado e compreensão ou entendimento (understanding) em se utilizando o recurso da argumentação no ensino de ciências, embora possa haver persuasão e convencimento através do uso de raciocínios mal construídos e com problemas na lógica argumentativa dos mesmos.

Mais do que a presença de falácias nos raciocínios dos estudantes dos três grupos, que eventualmente surgiram e são normais dentro dos processos de raciocínio, foi mais comum observar argumentos válidos nas argumentações, fossem os cogentes do grupo dos defensores da Missão Apollo, ou os não cogentes, mas no mais das vezes coerentes do grupo dos negacionistas, pois as conclusões falsas que eles tiravam eram a partir de premissas igualmente falsas; já os céticos, que funcionavam como uma espécie de juízes na dinâmica do debate, conforme já foi ressaltado anteriormente, suspendiam o juízo independente das premissas serem verdadeiras ou falsas. $\mathrm{O}$ critério de indecidibilidade entre as evidências disponíveis não permitia aos mesmos, racionalmente, uma tomada de decisão entre uma posição ou outra. Isto, do ponto de vista lógico e epistemológico, é bastante razoável, aceitável e mesmo legítimo, apesar de haver uma forte posição oficialista de se tomar como razoável, baseado em uma série de evidências fornecidas a eles através dos vídeos e dos textos apresentados, a veracidade da ida do homem à Lua. Embora se tomasse este ponto acerca da veracidade como a posição científica e oficialista como sendo a postura "correta", através da mediação do pesquisador, se procurou que isto não influenciasse o juízo dos alunos no júri simulado, no sentido de induzir as respostas em uma espécie de "viés da confirmação". Empiricamente o resultado se mostrou contrário a isto, com o grupo negacionista "vencendo" a discussão, e os céticos, apesar das considerações anteriores acerca da cogência de alguns dos seus argumentos, estarem um pouco alheios ao verdadeiro "espírito" da atividade, e podem-se apontar algumas razões para isto: uma delas pode ter relação com a própria forma como os materiais e recursos didáticos foram apresentados, motivando mais a posição negacionista e não tanto a oficialista, em uma espécie de inversão do ônus da prova, digamos assim, pois eram estes, no fim das contas, que tinham de rebater os argumentos dos negacionistas, e não o contrário. O jogo de confronto entre o que cada grupo considerava evidência ou contra-evidência no processo dialético-argumentativo, assim como razões favoráveis e contrárias aos seus respectivos pontos de vista, parece não ter fícado suficientemente claro e definido dentro de toda a dinâmica do júri simulado, influenciando direta ou indiretamente nos juízos e nos argumentos construídos, e isto repercutiu, também, na questão da motivação e engajamento, o mesmo se aplicando no caso da postura do grupo dos céticos, o que justificaria, em boa parte, esse relativo "distanciamento" dos mesmos em relação a estas questões. Outro fator talvez tenha a ver com os elementos motivadores em relação às escolhas de fazer parte deste ou daquele grupo: em uma situação mais idealizada, os alunos deveriam ter um contato prévio maior com o estado da arte da discussão e com os 
tópicos a fim de bem escolherem com mais convicção aquele ponto de vista que querem defender. Há boas razões para crer que esta postura faria os mesmos se engajarem com afinco nas suas argumentações, o que infelizmente não ocorreu neste micromódulo da maneira que se esperava pela falta de tempo já referida anteriormente.

Em relação à eficácia do modelo de Toulmin de argumentação aplicado na atividade e no júri simulado, este se mostrou bastante relevante e com resultados pertinentes para avaliação, apesar das limitações que tal modelo pode apresentar em situações reais de sala de aula, mas de uma maneira geral, como ferramenta de análise, mostrou-se útil e interessante no escopo da qual se determinou: se por um lado seu uso no presente contexto não permitiu que se retirassem conclusões mais consistentes sobre a sua eficácia plena em aula como instrumento metodológico, por outro revelou que pode e mesmo deve ser usado para este fim, com resultados minimamente satisfatórios, mesmo que de uma forma não tão definitiva e peremptória, o que requer mais ainda a sua utilização de forma prudente e responsável, seja em relação ao próprio recurso metodológico em sala de aula, e também na análise dos seus resultados, no caso os padrões dos argumentos e das argumentações produzidas pelos estudantes.

Resumindo, de maneira geral, pode-se dizer que, mesmo frente às limitações já referidas da aplicação deste micromódulo, a experiência foi válida e pode e mesmo deve ser expandida para uma análise mais aprofundada. Com os dados e os resultados obtidos deste estudo de caso, é bastante prematuro dizer se houve alguma espécie de aprendizado com sentido para os estudantes, mas tal prática parece ser um forte indicativo de que a argumentação e os debates orientados, como o júri simulado, são expedientes metodológicos bastante poderosos e estimuladores para o ensino de ciências, particularmente no contexto da educação básica, seja em atividades regulares da escola ou períodos de contraturno. O que podemos tirar como experiência desta narrativa para uma futura reaplicação é, tanto quanto uma elaboração acurada, detalhada e criteriosa dos materiais a serem utilizados em sala de aula, como os textos, vídeos e outros recursos pedagógicos, que são elementos necessários e fundamentais para as atividades propostas, visar estimular os estudantes levando-os a se engajarem e a se envolverem tanto com o tema a ser tratado como com os debates, que requerem preparação prévia por parte dos alunos e também dos professores que o utilizam, através do desenvolvimento de comprometimento, interesse e envolvimento com o tema no momento da atividade, seja o professor como moderador, sejam os alunos como agentes ativos e propositivos que tenham como intenção e objetivo a construção do conhecimento através da reflexão e do pensamento crítico, debruçando-se sobre o entendimento e a compreensão plenos dos problemas e das questões a serem trabalhadas. A eficácia e os ganhos cognitivos do processo argumentativo na educação científica são visíveis, e o seu estudo e a sua importância, seja como referencial teórico, metodológico e epistemológico, no sentido de verdadeiramente levar Epistemologia, História e Filosofia da Ciência para dentro da sala de aula, ou para contribuir na pesquisa em ensino de ciências, tanto na educação 
básica e também na superior, são fundamentais se desejarmos formar um educando que se configure em um cidadão crítico, responsável e contestador no meio em que atua e interage.

Em vista deste cenário de análise centrada no padrão de argumentação toulminiano, uma breve reflexão sobre os resultados obtidos, ainda que preliminares, pode ser feita no sentido de se pensar em alternativas para que a argumentação, ou metodologias semelhantes, possa ser mais efetiva e significativa em uma possível reaplicação do micromódulo aqui narrado, ou na aplicação de outros módulos semelhantes, tendo este mesmo contexto como padrão. Neste sentido, cabe chamar a atenção aqui para o chamado "ensino recíproco" de A. S. Palincsar e A. L. Brown (PALINCSAR, 1984; BROWN, 1988), referido por James Wertsch em seu livro "Voices of the Mind" (WERTSCH, 1993) em que a noção de diálogo em sala de aula é fundamental (baseada no conceito de dialogicidade proposto na filosofia da linguagem de Mikhail Bakhtin (BAKHTIN, 1981; 1986), seja entre professor e aluno e/ou entre os próprios alunos. Na metodologia do ensino recíproco na educação científica, que se aproxima bastante do ensino por argumentação, por propor uma compreensão de conceitos científicos ancorada em uma concepção de dialogia orientada, quem propõe o debate e o diálogo argumentativo, além do professor, são os alunos, que tem uma função essencialmente ativa nesse processo. Ao invés do professor conduzir o debate, esta iniciativa deve partir dos alunos, havendo uma espécie de divisão de tarefas na atividade. Nos estudos de casos promovidos por Palincsar e Brown, ao adotarem essa metodologia, constataram uma melhora significativa na compreensão dos assuntos discutidos em aula, especialmente no desenvolvimento de habilidades de leitura e compreensão de textos, que serviram de subsídio para o debate dialógico. Ao adotarem a postura de agentes ativos, e não apenas passivos no processo dialógico e argumentativo, os alunos passaram a ter um entendimento maior sobre tais assuntos, demonstrando desenvoltura e capacidade de compreensão, inclusive muitos assumindo o papel de líderes e condutores do debate.

No ensino recíproco, há propriamente esta dialogicidade bakhtiniana presente, pois muitas vozes e gêneros de fala, segundo terminologia do próprio autor, estão presentes, seja dos alunos e dos professores, e a direção de aprendizado não é unívoca, indo do professor para o aluno; ela vai também de aluno para aluno, onde não há passividade e sim atividade de todos os envolvidos; tanto o professor quanto os alunos são mediadores e construtores do saber, em um todo sistêmico e orgânico. Esta estratégia metodológica do ensino recíproco dialógico em consonância com a argumentação, igualmente dialógica e orientada, é a reflexão e sugestão final que fica para o melhoramento e aperfeiçoamento tanto da reaplicação do micromódulo aqui narrado, quanto da possível aplicação de outros módulos de ensino por professores interessados nesta estratégia, e que objetivem o aprendizado de ciências com sentido e na direção de uma formação crítica, responsável, autônoma e cidadã. 


\section{Referências bibliográficas}

BAEHR, J. Educating for Intellectual Virtues: From Theory to Practice. In Kotzee, B. Education and the Growth of Knowledge: Perspectives from Social and Virtue Epistemology, p. 106-123, Oxford: Blackwell, 2014.

BAKHTIN, M. M. The dialogic imagination: Four essays by M. M. Bakhtin. Ed. Michael Holquist, trans. Caryl Emerson and Michael Holquist. Austin: University of Texas Press, 1981.

BAKHTIN, M. M. Speech genres and other late essays. Ed. Caryl Emerson and Michael Holquist, trans. V. W. McGee. Austin: University of Texas Press, 1986.

BOARO, D. A.; MASSONI, N. T. O uso de elementos da História e Filosofia da Ciência (HFC) em aulas de Física em uma disciplina de Estágio Supervisionado: alguns resultados de pesquisa. Investigações em Ensino de Ciências, v. 23, n. 3, p. 110-144, 2018.

BRASIL. Diretrizes Curriculares Nacionais para a Educação Básica (DCNEB). Ministério da Educação, Conselho Nacional de Educação. MOLL, J. (Org.) 2013.

BRASIL. Ministério da Educação. Base Nacional Comum Curricular. Brasília, 2018. Disponível em:

$<$ http://basenacionalcomum.mec.gov.br/images/BNCC_EI_EF_110518_versaofinal_site.pdf $>$ Acesso em: 15 abr. 2020.

DRIVER, R.; NEWTON, P.; OSBORNE, J. Establishing the Norms of Scientific Argumentation in Classrooms. Science Education, v. 84, Issue 3, p. 287-312, 2000.

FENSHAM, P. Scepticism and Trust: Two Counterpoint Essentials in Science Education for Complex Socio-Scientific Issues. Cultural Studies in Science Education, v. 9, n. 3, p. 649$661,2014$.

GEACH, P. Razão e Argumentação. Editora Penso, 2012.

GOLDMAN, A. Knowledge in a social world. Oxford: Oxford University Press, 1999.

GOMES, T. G.; BARBOZA, L. C. Uma proposta de júri simulado como estratégia lúdica para ensino de história da química no ensino médio: a teoria do flogístico. In: ENCONTRO PAULISTA DE PESQUISA EM ENSINO DE QUÍMICA, VII, 2013. Atas... 
HODSON, D. Going Beyond CTS: Towards a curriculum for sociopolitical action. The Science Education Review, v. 3, n. 1, 2004.

KOLSTO, S. Scientific Literacy of Citizenship: tools for dealing with the science dimension of controversial socioscientific issues. Science Education, v. 85, n. 3, p. 291-310, 2002. Disponível em: <https://doi.org/10.1002/sce.1011>.

KUHN, D. Science as argument: implications for teaching and learning scientific thinking. Science Education, v. 77, n. 3, p. 319-337, 1993.

KUHN, D. The Skills of Argument. New York: Cambridge University, 1991.

KUHN, D.; HEMBERGER, L.; KHAIT, V. Argue with Me - Argument as a Path to Developing Students' Thinking and Writing. Bronxville, N.Y: Wessex, 2014.

LEDERMAN, N. G. Students' and teachers' conceptions of the nature of Science: a review of the research. Journal of Research in Science Teaching, v. 29, n. 4, p. 331-359, 1992.

MASSONI, N. T. A epistemologia contemporânea e suas contribuições em diferentes níveis de ensino de física: a questão da mudança epistemológica. 2010. Tese (Doutorado em Física) - Universidade Federal do Rio Grande do Sul, Porto Alegre.

MATTHEWS, M. R. História, filosofia e ensino de ciências: a tendência atual de reaproximação. Caderno Catarinense de Ensino de Física, v. 12, n. 3, p.164-214, 1995.

MERCER, N. The guided construction of knowledge. Clevendon, Multilingual matters Ltda, 1995.

NASCIMENTO, S.; VIEIRA, R. Contribuições e limites do padrão de argumento de Toulmin aplicado em situações argumentativas de sala de aula de ciências. Revista Brasileira de Pesquisa em Educação em Ciências, v. 8, n. 2, p. 1-20, 2008.

PALINCSAR, A. S.; BROWN, A. L. Reciprocal teaching of comprehension- fostering and comprehension-monitoring activities. Cognition and instruction, v. 1, n. 2, p. 117-175, 1984.

PALINCSAR, A. S.; BROWN, A. L. Teaching and practicing thinking skills to promote comprehension in the context of group problem solving. RASE, v. 9, n. 1, p. 53-59, 1988. 
PLANTIN, C. Lengua, argumentación y aprendizages escolares. TED, n. 36, p. 95-114, JulDec. 2014.

ROSSATO, R. Século XXI: saberes em construção. Passo Fundo: UPF, 2002.

SANTOS, W. L. P.; MORTIMER, E. F.; SCOTT, P. H. A argumentação em discussões sóciocientíficas: reflexões a partir de um estudo de caso. Revista Brasileira de Pesquisa em Educação em Ciências, v. I, n. 1, p. 140-152, 2001.

SASSERON, L. H.; MACHADO, V. F. Alfabetização científica na prática: inovando a forma de ensinar física. 1. ed. São Paulo: Editora da Física, 2017.

SIEGEL, H. Truth, thinking, testimony and trust: Alvin Goldman on epistemology and education. Philosophy and Phenomenological Research, LXXI, p. 345-366, 2005.

SILVA, B. V. C.; MARTINS, A. F. P. Júri simulado: um uso da história e filosofia da ciência no ensino da óptica. Física na Escola, v. 10, n. 1, p. 17-20, 2009.

SMITH, M. U.; SIEGEL, H. Knowing, believing, and understanding: what goals for science education? Science \& Education, v. 13, p. 553-582, 2004.

SOLOMON, J. About argument and discussion. School Science Review, v. 80, n. 291, p. 57 62, 1998.

STUMPF, A.; OLIVEIRA, L. D. Júri Simulado: o uso da argumentação na discussão de questões sociocientíficas envolvendo radioatividade. Experiências em Ensino de Ciências, v. 11, n. 2, p. 176-189, 2016.

TOULMIN, S. Os usos do argumento. Trad. R. Guarany. São Paulo: Martins Fontes, 2001. (Tradução do original inglês The uses of argument, Cambridge: Cambridge University Press, 1958).

WERTSCH, J. Voices of the Mind: A Sociocultural Approach to Mediated Action. Cambridge Massachusetts: Harvard University Press, 1993.

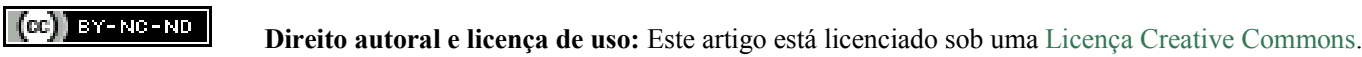

